\title{
Bumblebee Predators Reduce Pollinator DENSITy AND Plant Fitness
}

\author{
REUVEN DUKAS $\downarrow$ ANIMAL BEHAVIOUR GROUP $\uparrow$ DEPARTMENT OF PSYCHOLOGY \\ NEUROSCIENCE \& BEHAVIOUR $\uparrow$ MCMASTER UNIVERSITY \\ 1280 MAIN STREET WEST $\uparrow$ HAMILTON $\uparrow$ ONTARIO $\uparrow$ CANADA
}

\begin{abstract}
$\uparrow$ ABSTRACT
Research in pollination biology has focused on the interactions between animals and the flowers they visit for food reward. However, other selective agents, including predators, seed feeders and herbivores, may affect pollination systems. Because flowers are predictable food sources for a variety of species, flowers are also reliable sites at which predators can locate flower-visiting animals. Prominent among pollinators' predators are beewolves (Philanthus spp), common sphecid wasps (Sphecidae) that prey almost exclusively on bees. My field work over three years indicates, first, that an area of approximately 50 square $\mathrm{km}$ surrounding a single bumblebee wolf (Philanthus bicinctus) aggregation had a low bumblebee (Bombus spp) density caused by intense predation by the wasps, and, second, that fruit set of the bumblebee pollinated western monkshood (Aconitum columbianum) was significantly lower at locations and times of bumblebee wolf activity than at control locations and times with no such predatory activity. These results indicate that predation can sometimes alter plantpollinator interactions.
\end{abstract}

\section{$\downarrow \quad$ INTRODUCTION}

The interactions between animals and flowers have been subjected to many classic studies in ecology and evolution. Recently, there has been increased interest in broadening the traditionally narrow focus of pollination biology to include additional trophic levels and whole-community interactions. Examples include studies examining the effects of pollinators' predators, seed predators and herbivores on floral traits (Dukas 2001a \& b, Irwin et al. 2004). Whereas it is convenient to focus on only the two obvious players, flower visitors and flowers, it is clear that other agents may sometimes shape pollination systems. To quantify the effects of bee predation, I tested whether predatory activity by bumblebee wolves ( $P$. bicinctus) was negatively correlated with (i) bumblebee density at flower patches of three common plant species, and, (ii) fruit production of the bumblebee pollinated western monkshood (Aconitum columbianum).

\section{$\downarrow$ MeTHODS}

The research was conducted within a distance of $6 \mathrm{~km}$ from a single bumblebee wolf aggregation along the Snake River in North Western Wyoming, USA in summers 2002-2004. The bumblebee wolf aggregation, previously studied by Armitage (1965) and Evans and O'Neill (1988), contained a few hundred active nests spread over an open sagebrush (Artemisia tridentate) field a few hundred meter in diameter. Each season, the bumblebee wolves were active from late July to late August, capturing small and medium size worker and male bumblebees at flowers (Fig. 1).

I compared bumblebee activity on goldenrod (Solidago sp.) and western rayless coneflower $(R$. occidentalis) near and far from the beewolf aggregation in August 2002 and August 2003 respectively. I also monitored bumblebee 
activity on and fruit set of Western monkshood ( $A$. columbianum), a self-incompatible, classic bumblebee pollinated plant. I conducted two sets of comparisons. The first set was carried out in July, before the start of bumblebee wolf activity. The second set was conducted during peak bumblebee wolf activity in August.

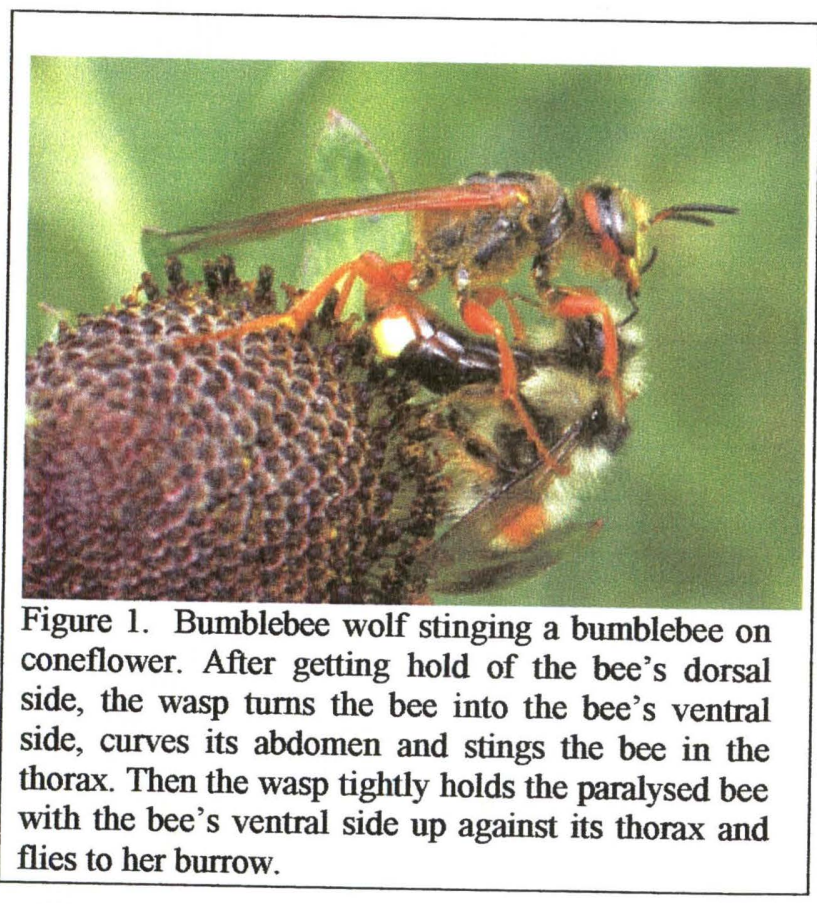

Finally, I followed focal wasps engaged in hunting behavior on coneflower. For each focal wasp observed, I recorded all encounters with bumblebees and classified each as either success or failure. To supplement the focal observations, I also recorded the rate of prey delivery to the wasp aggregation during a one-hour period in 6 days.

\section{$\downarrow \quad$ RESULTS}

I recorded 14 times more bumblebees at coneflower patches far from than near the beewolf aggregation (Repeated measures ANOVA, $\mathrm{F}_{1,10}=74$, $\mathrm{P}<0.001$ ), and 26 times more bumblebees at the far than near goldenrod patches (Repeated measures ANOVA, $\left.\mathrm{F}_{1,10}=7, \mathrm{P}<0.05\right)$. In monkshood, I recorded twice as many bumblebees far from than near the bumblebee wolf aggregation during peak wasp activity in August (Repeated measures ANOVA, $\mathrm{F}_{1,10}=7, \mathrm{P}<0.05$ ). In contrast, I counted similar numbers of bumblebees at monkshood patches far from and near the beewolf aggregation-site before the onset of beewolf activity in mid-July (Repeated measures ANOVA, $\mathrm{F}_{1,10}=0.02$, $\mathrm{P}>0.9$, Fig. 2).

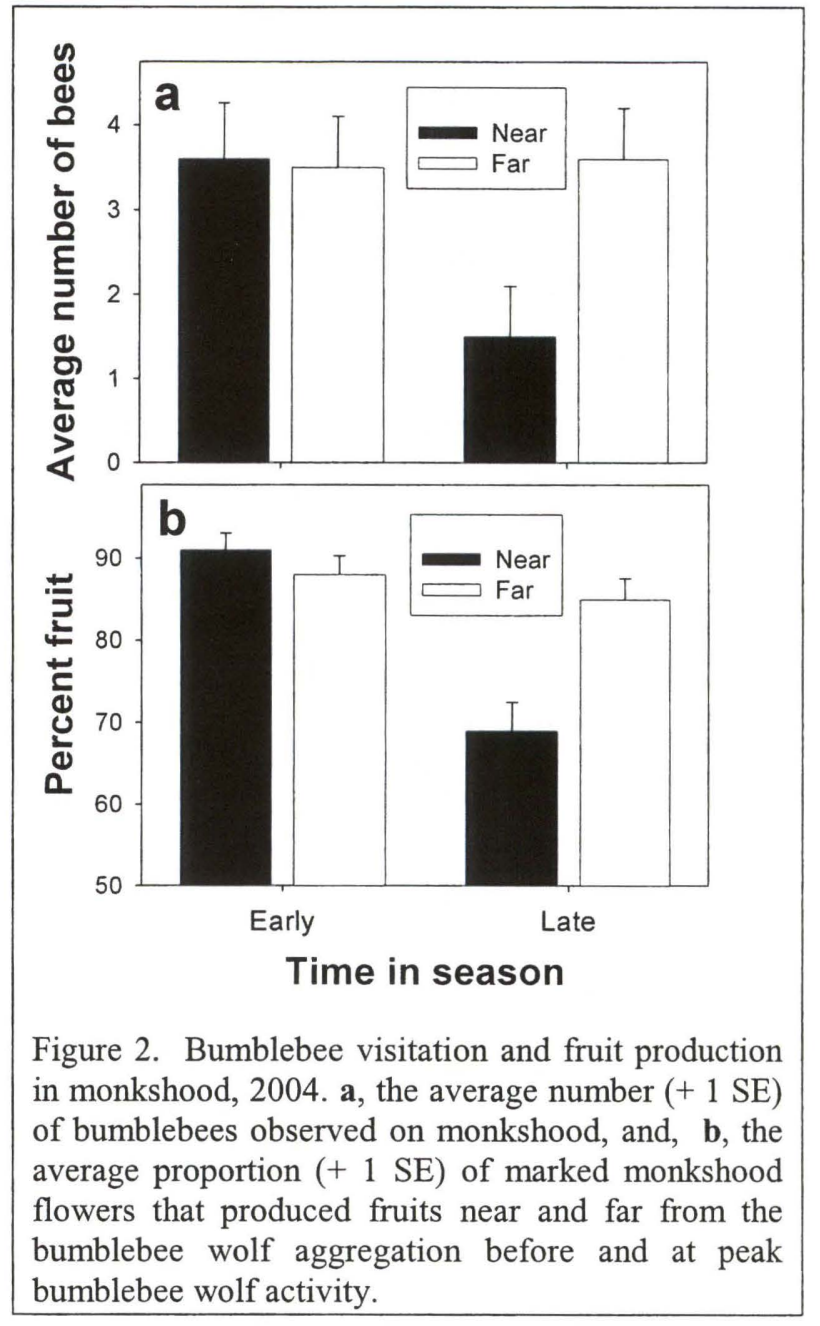

Predatory activity of bumblebee wolves was negatively associated with fruit set of the predominately bumblebee pollinated monkshood. In 2003, the proportion of monkshood flowers that produced fruits was twice as high far from than near the beewolf aggregation $\left(\mathrm{F}_{1,191}=20.8, \mathrm{P}<0.001\right)$. The other 2003 comparison of monkshood fruit set also revealed significantly higher fruit set far from than near the wasp aggregation $\left(\mathrm{F}_{1,198}=12.3, \mathrm{P}<0.001\right)$. In 2004, I recorded significantly higher fruit set in monkshoods far from than near the bumblebee wolf aggregation during peak wasp activity in August (ANOVA, $\mathrm{F}_{1,196}=15, \mathrm{P}<0.001$ ). In contrast, similar proportions of monkshood flowers set fruit far from and near the beewolf aggregation before the onset of beewolf activity in July (ANOVA, $\mathrm{F}_{1,195}=0.9, \mathrm{P}>0.3$.

Thirty two percent of the 257 wasp attacks I observed were successful. I recorded bumblebee responses to failed wasp attacks in 61 encounters. In $59 \%$ of these encounters, the bumblebees merely flew to nearby flowers and resumed feeding. The 
other encounters resulted in the bees departing from the patch. The average $( \pm 1 \mathrm{SE})$ hourly prey delivery rate to the center of the bumblebee wolf aggregation was $199 \pm 28$ in 2003 and $850 \pm 97$ in 2004. Of the 87 victims I inspected closely, all but two were bumblebees.

\section{$\uparrow \quad$ DISCUSSION}

All lines of evidence indicate that the bumblebee wolf activity was associated with low bumblebee abundance and reduced fruit set in the bumblebee pollinated monkshood within an area of about 50 square $\mathrm{km}$ surrounding the single wasp aggregation. First, delivery rates to the wasp aggregation were as high as 1015 bumblebee prey per hour. Second, I directly observed over 250 wasp attacks at flowers near the aggregation and witnessed rapid declines in bumblebee densities directly linked to the commencement of beewolf predatory activity. Third, I recorded no differences in bumblebee abundance near and far from the aggregation before the start of wasp activity but found large differences a few weeks later. Finally, there was no difference in flower phenology between the near and far areas. This is indicated by the nearly identical numbers of flowers on near and far monkshood plants and the fact that all patches of the three plant species observed were closely matched in phenology.

The reported high predation rates by bumblebee wolves raise two obvious questions. First, did bumblebees show behavioral avoidance of bumblebee wolves, and, if not, why? Whereas direct effects of the predators were clearly dominant, I have no evidence for indirect effects caused by bumblebees permanently fleeing the high-predation area. First, about $60 \%$ of the bees experiencing failed wasp attack resumed foraging within the same patch. A few times I watched a bee continuing foraging after a failed wasp attack and instantly being attacked again by the same wasp. Second, in many cases, bumblebees struggling with beewolves released large amounts of alarm pheromone, which I could readily smell. This, however, did not result in fleeing of the other bumblebees from the patch. Bumblebees typically encounter a variety of sphecid wasps feeding on nectar at flowers. Perhaps bumblebees do not distinguish between such harmless encounters with nectar-feeding wasps and predation attempts by bumblebee wolves.
The second inevitable question is how are local bumblebee densities maintained over years in face of high predation rates by the bumblebee wolves? Two factors probably contribute to the yearly renewal of bumblebees near the beewolf aggregation. First, the wasps begin activity relatively late in the bumblebee colony cycle, which allows some level of queen production. I have observed numerous male bumblebees during peak activity of the wasps at flowers near the aggregation and as prey delivered to the wasps' nests, which suggests relatively high levels of reproductive production near the aggregation. Second, queen bumblebees flying from locations far from the wasp aggregation may recolonize the area near the aggregation every spring.

Finally, the broad question raised by this study is the generality of my finding. In other words, what proportion of plant communities are affected by predation on pollinators and how strong are the effects? Whereas it is premature to answer this question given the limited data available, it is relevant to note that tradition, the convenience of focusing on only two trophic levels, and practical difficulties of observing predation events may have caused pollination biologists to underestimate the importance of predation on pollinators.

In sum, intense predatory activity by bumblebee wolves resulted in low numbers of bumblebees and low fruit set in the bumblebee pollinated monkshood at the vicinity of the wasp aggregation. The ubiquity of bee wolves and other pollinators' predators suggests that the threat of predation is sometimes an important selective force affecting pollination systems.

\section{$\downarrow$ ACKNOWLEDGEMENTS}

L. Taylor and S. Myles assisted in the field. L. Harder identified the bumblebees. M. Daly, R. Cartar, D. Morse and anonymous referees commented on the manuscript. H. Harlow and staff at the University of Wyoming - National Park Service Research Station provided superb hospitality, and the US National Park Service issued research permits. I have been supported by the Natural Sciences and Engineering Research Council of Canada, Canada Foundation for Innovation, and Ontario Innovation Trust. 


\section{$\downarrow$ LITERATURE CiTED}

Armitage, K. B. 1965. Notes on the biology of Philanthus bicinctus (Hymenoptera: Sphecidae). Journal of the Kansas Entomological Society 38:89-100.

Dukas, R. 2001a. Effects of perceived danger on flower choice by bees. Ecology Letters 4:327-333.

Dukas, R. 2001b. Effects of predation risk on pollinators and plants. Pages 214-236 in L. Chittka and J. Thomson, editors. Cognitive Ecology of Pollination. Cambridge University Press, Cambridge.
Evans, E. E., and K. M. O'Neill. 1988. The Natural History and Behavior of North American Beewolves. Cornell University Press, Ithaca.

Irwin, R. E., L. S. Adler, and A. A. Agrawal. 2004. Community and evolutionary ecology of nectar. Ecology 85:1477-1478. 